\title{
PANEL DISCUSSION OF QUESTIONS SUBMITTED AT THE CLOSING \\ SESSION OF THE ANNUAL MEETING OF THE CANADIAN ANAESTHETISTS' SOCIETY JUNE 23, 1955
}

\section{Chairman Dr. B. C. LEECH, O.B.E, M.D, C.M., F.F.A.R.C.S.}

THE PANEL as we propose to present it is quite a departure from ordinary panel or Round Table discussion techniques, in that I am throwing these experts to you to be sniped at, all ten of them, from any angle you wish in the whole field of Anaesthesia. That is quite unusual and a new departure, I think, in panel discussions. It has been suggested that we try this once, and see if it is advisable at the end of a two- or three-day conference in order to help clear up any misunderstanding that might exist in reference to the papers which have been presented, or some question that you came prepared to get an answer to, and which unfortunately was not dealt with during the course of the convention. The members of our panel include five from the United Kingdom, and five from Canada; among them we have a lady from each side of the Atlantic. I shall introduce them, and I wish they would stand so that you can remember well who they are, as I call their names. First those from the United Kingdom: Dr. Sheila Anderson of London, interested in paediatric and neurosúrgery anaesthesia. Dr. R. W. Cope of London-he is partıcularly interested in sae Jiatric and acute abdominal work; Dr. Langton Hewer of London-if you try the J.A. examination sometime in London you will certainly meet him; Dr. Geoffrey Organe, whom you have already met [ am sure; Sir Robert Macintosh the Professor of Anaesthetics at Oxford University. And now the Canadian members: Dr. Donalda Huggins of Winnipeg, Chief of the Department at Winnipeg General Hospital, and Senior Teacher at the University of Manitoba Medical School; Dr. Ted Gain of Edmonton, Head of the Department of Anaesthesia of the University of Alberta; Dr. AR. A. Gordon of Toronto who needs no introduction to any of us; Dr. Gordon Wyant, Professor of Anaesthesia, University of Saskatchewan; and Dr. Léon Longtin, University of Montreal.

We have a whole sheaf of questions which we shall try to cover well within the hour allowed to us Some of these I have put names on, and some of the panel members have agreed as I have designated therr questions. Others have objected: many questions they have never seen before, and questions have been arriving until 2:00 o'clock today. I hope to start out with something we can cover rather quickly, and thus get into the swing of things. I would request that any comments from the floor be held until the whole panel is over because your point may be covered by the next speaker.

Let us start off with Dr. Organe and Dr. Gordon, and ask them some of the questions which have been submitted.

\section{QUESTION 1}

"What proofs are there that muscle relaxant drugs do not pass a placental barrier in sufficient concentration to affect the foetus whic 1 will be delivered either by Caesarean or per vagina within fifteen minutes? 
Dr. ORGane: While I will not talk of any proof, experimental work has been done, particularly on the rabbit foetus and it shows, as I think, that as far as. that work went, no significant amounts passed the placental barrier. Since relaxants came in, at least since this animal work was done, I have used muscle relaxants in all Caesarean sections, and my impression has been not that the infant has been in any way weakened by muscle relaxants, but that owing to the very much lighter anaesthesia which we have been able to use with the aid of muscle relaxants, the children have breathed more quickly and have been more vigorous afterwards than they have been with ordmary general anaesthesia; to my mind, on clinical grounds at any rate, using munimal quantities of muscle relaxants, there is no evidence at all that the child is in anyway affected by any of the muscle relaxants.

Dr. Gordon. Mr. Chairman, I might say that this is a surprise to me because. I said I could not answer this the last time I talked to you. I gather that the question means absolute proof in the matter of the passage of muscle relaxants through the placenta. There is in fact, I think, jretty fair proof that muscle relaxants do pass through the placental barrier anc that the question of whether or not they are detrimental to the foetus depends on the concentration which the infant receives. There has been work reported from the University of Iowa, which Professor Lucien Morris discussed at the meeting of the Canadian Anaesthetists' Society two years ago, and those of you who were there at that time may recall that the point of the matter was that the muscle relaxants could be identified in the placental circulation after being given intravenously to the mother, but that no significant concentration had been demonstrated excejt ifr cases where it was injected into the uterine artery, which of course is qui.e an impractical procedure in clinical anaesthesia.

\section{QUESTION 2}

Dr. LeECH: Here is a question from an obstetrician.

"What method of anaesthesia is advised as the best for the ante-partum external version manipulation when the presenting part is engaged?"

Dr. Cope, can you start us off on that?

DR. Cope. I think so, Sir, but my answer will be a brief one. I think the method is Chloroform, in one word.

Professor Macintosh. Well I don't know whether it is because one has become a little more bald-headed than Senior, but I don't think I have been called in for an external version when a part has already presented

Dr LEECH. Engaged, Sir.

Professon Macintosh. Yes, I am just wondernng whether, on the question of the ordinary external version, a tip is worth passing on that you don't know about. Some, of course, are extremely easy, and some impossible; but in between there is the patient who has the combination of a tight uterus and a tight abdominal wall, and we have found effective what we would call a small dose of Pentothal (that is anything up to half a gram) to relax the uterus, and a full dose of relaxant for the abdominal wall. I notice my colleague here from England talked about minimal dose of relaxants. In America that is 2 or $3 \mathrm{mg}$. 
of Curare. I think Dr. Geoffrey Organe had in mind 15 or $20 \mathrm{mgm}$. Certainly in talking about versions I have doses of that magnitude in mind.

Dr. LEECr: Sir Robert, I forgot that you had asked to speak on the former question. Would you like to add anything to Dr. Organe's or Dr. Gordon's remarks concerning the relaxant drugs passing the placenta?

Professon Macintosh. I did that very thing, Sir, when I told Dr. Organe that I think that "minimal" doses of Pentothal and Curare vary greatly with the country from which you come. When I was in New York there was a bit of discussion there whether fifteen or twenty mg. of Succinyl Choline should be given, and I said why not give 100 as everyone does. They thought that that was too bad. The same applies, I think, to Curare. The other point of the question concerned proof. It is a funny thing thst I have not had Curare blamed for depression of the foetus; and I know that in our group of hospitals we have been using the relaxants for ten years for Caesarean section, as far as we know with satisfaction, and no blame for anything has attached to it.

\section{QUESTION 3}

"List the requirements for efficient cardiac massage."

Dr. Gordon Wyant. Well, there must be some idea implied that I am a particular specialist in cardiac massage. I hope I am not. I believe that there are two essental criteria for efficient cardiac massage; you must be able to obtain an adequate blood pressure and pulse. You remember that cardiac massage is carried out with the purpose in mind of restoring the oxygen-carrying system by artificial regulation of the circulation. Therefore we must be able to be sure that it is efficient; the peripheral pulse must therefore be felt and blood pressure should be found obtainable.

DR LEECH. Anything short of that you have stated would be inefficient?

Dr. Wyant. That is correct.

Dr. Orgañe Like Dr. Wyant I disclaim any experience in this, because I am actually inexperienced But from what I have read in text-books, I have taught that cardiac massage should be carried out at a fairly slow rate, because with no back pressure in the veins it takes some time for the auricles to fill and for the ventricles to fill, in order that the next pulse wave that goes out should contain a reasonable amount of blood. But on the one occasion when I dic myself do some cardiac massage, the child died under anaesthesia for tonsi operation. After some time it was quite evident that the child would not live so we tried cardiac massage. I was surprised how easily it was possible to obtair quite an efficient artificial circulation. We continued artificial respiration with oxygen and if the massage was carried out inefficiently or stopped for a while everything would go blue, but you could even get the fingernails pink compara. tively easily by doing cardiac massage, the man who was most efficient at this was the man who was doing the massage at a rate of about 80 times per minute. This was a child, and it may be that in a child a rapid rate is more appropriate than in an adult. I do not know. What I do know is that after a prolonged period of cardiac massage the heart was grossly damaged. 
DR. Donalda Hugcrns. I think one of the requurements is making a diagnosis. You massage the heart all you like without success if you have missed the time when it was going to do any good. I think that one should always be alert and ready, watching for cardrac arrest, and have the equipment in the room to do cardiac massage I should like to divide it into three minutes, and let each minute have some particular part to play in the successful outcome. I think each person in the operating room also has a part to play. One nurse should be assigned to count off the seconds, five, ten, fifteen, because often when such an emergency occurs everyone forgets the passing of time. Another thing is to have cardiac massage (thoracotomy) equipment avallable readily. Thirdly, the anaesthetist, if he is with an otolaryngologist certamly will many times have to take over the massage or the supportive measures, and so he must remember that the minutes are passing. If he has to pass over the oxygenation of the patient to someone else and do the thoracotomy and cardiac massage himself, he must have the assistant available to take over the massage also, because your hands get very tired massaging a heart through a chest wall.

\section{QUESTION 4}

Dr. LeEch Now a question on the same subject.

"What should be accepted as the safe and sound criteria for abandoning further resuscitative measures in a case of cardiac arrest?"

I feel that this is an important question and deserves an important answer, and one which could well make medical-legal history. I have asked Dr Hewer to give us the first answer.

Dr. HewEr. While I don't want to make medical-legal history on this subject, a lot of the points, I think, have been covered by the previous speakers. The essential time, it seems to me, is before the cardiac massage starts. The cells of the cerebral cortex have only a very imited period when they remain viable with no circulation, and that is the essental time limit. You could go on doing cardiac massage for months if you have exceeded that time limit and the patient will never recover. He may become a sort of a decerebrate animal and get reflexes back, but that isn't much good There is one point regarding the actual doing of the cardiac massage which hasn't been mentioned: that is, that a good deal of work has been done on the subject showing that the essentral feature of the cardiac massage is the maintenance of pressure in the coronary arteries. If you can raise the coronary pressure the heart will probably start, and you can raise that pressure very considerably if it is possible to squeeze the aorta at the same time as the cardiac massage is done. Now that is probably impossible if you are doing the cardiac massage through the diaphragm, but if the chest wall is open, then I think it is well worth getting an assistant to put a good deal of pressure on the aorta while the cardiac massage is being done. Then the coronary pressure will rise and you have much more chance of starting the heart. You will see I have very skilfully avoided this issue I haven't said anything about limiting criteria, but I have thought that while there is evidence of an efficient artificial circulation it is worth going on If the mucous membranes are pink, if 
pressure on them produces blotching which disappears on removal of pressure, Lwould think it is worth continuing carcliac massage-but the minute this stops I think it is quite useless to go on. I do not think that one can possibly give a tme limit To start with, why did the heart stop in the first place? It may be due to all sorts of things. It may be due to exsangunation and if that is the factor which has caused the heart to stop, it has to be removed. It may be a reflex effect, with chloroform or adrenalin or something of that sort I do not think it is possible to give a tme limit, but I would suggest that the criteria should be clinical as I have tried to indicate

Dr LÉon Longtin To give specific criteria is very hard in my opınıon Time lapse since the heart stopped is not a criterium, because there are cases reported of recovery after thirty or orty minutes of massage or resuscitation measures. Perhaps dilatation of the pupils would be a criterium, but this must be correlated with the drug the patient received before and the depth of anaesthesia. The consistency of ocular globes may be one criterium. About one year ago I had a case that was already surgically completed, and suddenly when taking the blood pressure I realized there was no blood pressure or pulse. I had the surgeon who was operating check the pulse, but there was none. We started cardiac massage right away In the meantime the patient was still breathıng and he kept on breathing. We gave him some blood. The thing went on for about forty-five minutes The heart was then massaged but as soon as this was stopped the beats were slower and slower and the heart would stop again. We did this for four hours, and the patient was breathing all the time. The surgeon was getting tred, and asked, "when are we going to stop?" I told him we could not stop, because thıs patient was not dead and was still breathing. We kept on like this for ten hours. The patient died after ten hours, and the post-mortem revealed that this patent had a cardiac infarction twenty-four hours before operation. It was almost impossible to live with such important damage.

DR. LEECH Sir Robert, can you help us on this?

Professor Macintosh I would have suggested in this last case of Professor Longtin's that there must have been some circulation for the man to continue breathing I know even Koster in the old days of spinal anaesthesia had many patients on whom he couldn't record a blood pressure, the spinals went very high. When his attention was drawn to that he said "It's all night I can feel some beat in the aorta", so we can survive with extraordinary low pressures. As far as answering this question specifically I don't suppose there can be any precise answer I think most people today are quite satisfied when they come up to a person whether he is dead or not, and yet in the old days I can remember lots of people who used to leave money in their wills for the doctor to cut the artery to make sure they were dead before they were buried, and I have a letter from an old man in Vienna who tells me that in the post-mortem room there they used to have a rope that they tied around the corpse's hand at night in case he woke up, it would appear that in those days certain people (whether due to inferior medicine or not) were certified as dead :when they were not. Certainly when I have seen cardrac massage carrned out it has always been carried out for many minutes after one has felt that the thing was completelv 
hopeless. I would have differentiated as Dr. Hewer does on the cause of the arrest. I should think if anyone dies from Pentothal, ether, or Cyclopropane as they did in the old days, then any massage longer than a few minutes was doomed to hopelessness. But on the other hand I do know of a heart being operated on, and when, very likely owing to surgical manipulation, the heart stopped, cardiac massage was carried out for twenty minutes and the patient recovered. The very strikng thing is that in this case massage was very efficient because the boy made a completely uninterrupted recovery and was discharged at the usual time, but the curcumstances were ideal because the pericardium was already open and skalled people were at hand.

Dr. LeEch. Dr. Hewer and Professor Macintosh have each indicated that as long as efficient circulation can be maintained the case should not be abandoned. I wonder if we could describe what might be considered efficient? We heard a description of efficient cardiac massage previously. I would suggest that if our efforts at cardiac massage cannot produce a palpable pulse either in the radial artery or in the neck vessels something has happened, and I think that what must have happened is that the heart is no longer filling, and therefore you cannot get any blood out of it. I think perhaps that this question might be quite acceptably answered on that basis: If the heart no longer fills, nor can be made to fill by slowing up our timing a little, that we are then quite justified in abandonment; I think that would be acceptable to medical-legal au hority if it receives general support. Do you think such a defintion would bear medical legal support in England, Professor Macintosh?

Professor Macintosh. The only thing is that I don't know how you are to tell when the heart is filling I know the cardiac massage can be effective. I know a patient who died under "secondary saturatıon" in one of the services, and he was inflated with oxygen and of course nothing happened; then when the surgeon started cardiac massage he became a beautiful colour, but it was quite ineffective. I just don't know, Sir, what critenum you are going to take for the heart filling. Would the panel like to express themselves?

Dr. Longtin. Yes, I should like to ask the Chairman to have Dr. Vandewater tell us the story of a patient they call "Lazarus."

Dr. LEECH. Can we reserve that for the cocktall party?

DR. Longtin. Yes.

\section{QUESTION 5}

Dr. LEECH. To change the subject now, we have a question with a little spike of military in it.

"Much as we dread the thought, another great war in our time is considered a distinct possibility. As anaesthetists, how should we be thinking, planning and teaching in preparation for anaesthesia services both military and civil?"

I should like to ask Dr. Gordon to commence this because I know he was adviser to the Director General Medical Services (Canada) on table for anaesthetic equipment and so on. I think he can start us off very nicely. 
Dr. Gordon. Mr. Chairman, this is a very large question. This problem has been dealt with in part in this meeting by three or four speakers, and I think that the answer will resolve itself into three parts. First is the provision of personnel, who are adequately trained to cope with the anaesthetic problems in disaster situations, whether they be civil or miltary. The second part concerns equipment and the type of equipment which they would expect to use, or which they may expect to have. The thurd is related to the problem of supply under disaster circumstances. As far as personnel are concerned, I believe that Dr. Gain's theme in his paper yesterday in dealing with anaesthetic deaths in the Province of Alberta, that every doctor should be trained to a state of competence to do simple anaesthesia, is the most inportant fact to remember. As far as disaster sttuations in the civil population are concerned, that training may be of the utmost importance. We all know that our traned anaesthetists are likely to be concentrated in larger hospitals or un the hospitals of an area where disaster strikes us. Very few of them may survive the first blow and it is quite evident that someone else must carry on. It may even be evident if we think a little farther that some of these people with a minmum of training will have to carry on with lay assistants. For that reason the question of equipment is very important. Most of these people will not be adequately trained to deal with elaborate anaesthetc techniques. Professor Macintosh this morning brought this home to us in his discussion on simplicity in anaesthesia. I am not sure whether we can count on them having as pretty a prece of apparatus, Sir Robert, as this beautiful vaporizer and ventilating equipment you have shown us. I am quite sure most such equipment will be found stored in hospitals and will likely not be available when it is most required. I think that in these people who may be responsible for carrying on the anaesthetic services to a population involved in a disaster the faculty of improvization is most important. We all know of people who must have an endotracheal tube, who insist on a Charles King No. 10 Magill before it would be considered an endotracheal tube, when in fact there may be lots of rubber tubing around which will serve the same purpose if it is essential for this to be used. The same thing holds for ether vaporizers An old tin can out of the neighbouring garbage pail may be converted into an ether vaporizer if this should be necessary. I think we must teach our medical population to recognize first the danger signs in anaesthesia. I don't know how far we could go in teaching elaborate methods of getting out of trouble when trouble occurs, because in these situations it is probable that most of them won't get out of the trouble anyway. I am not sure that the better attitude is not to teach people to recognize danger and at that point to desist, and wait until things correct themselves. The question of supply is a double problem of avallability and transport. That occurs in mulitary situations. It may not occur in the R.A.F., Sir, or it may not occur in the Navythey take all sorts of things along with them. I think there may be some people in this room who were in Italy and found that when General Montgomery wanted shells transported, oxygen, nitrous oxide, 'and such things didn't matter a bit, and you could work with your bare hands for all that that mattered. I think we must go back to consider the use of agents which are likely to be transported in small space, which won't involve great weight, in transport, and which are likely 
to be obtainable from muxed sources, and although I am sure that are some people who will shudder at the suggestion, and Dr. Jarman may be one of them, I think that we will have to rely on ether and perhaps chloroform if we can find it. Certanly I think that ether is likely to be the most readily avarlable anaesthetic agent in these situations. I thunk, Mr. Charman, that is all I will say on this problem, I have used up more than my time.

DR LEECH Thank you, Dr. Gordon.

Dr LEECH Dr Cope has some connection with the RAF, I believe. Can you help ùs on this?

$D_{R}$ Cope Mr Chairman, my connection was not with the R.A F. but the Army Medical Services in the R A M.C., and what I can add is based on that experience of some years ago. Two points I should like to make, both of them to reinforce very sincerely Dr Gordon's remarks. First about personnel-these remarks are made solely with regard to the Armed Forces in the field. I think that it is essential not to put your most junor trained anaesthetssts or surgeons in field units; a very high portion of trained surgeons and trained ahaesthetists were put into units called Field Surgical Units grouped around a larger unt first called a Casualty Clearing Station and then the Advanced Dressing Station To think that because a man is young he is the most fit and is therefore the man to send forward may very well jeopardize the chances of survival in your massive or major battle casualties They need surgical judgment and experience based on ordinary civilaan experience coupled with the necessary technical skill. This, I think, applies very strongly to anaesthetssts who are, at the same time, just as in civilian practice, partially resuscitation officers. So don't send your junior men forward, keep them under traming and gettng more experience urth some skilled people in general hospitals. As regards equipment, again I reinforce almost entrely what Dr. Gordon says. simplicity, I believe, above everything I think that the greatest simplicity is a couple of syringes, some Pentothal, and if possible a supply of relaxants and some means of inflation. In the last war, Professor Macintosh produced a beautiful piece of apparatus for anaesthesia called the Black Kettle, sometumes called the Oxford Vaporizer, and we used it, of course with ether, and found it a great God-sent blessing (despite some accidents when you tipped it up and threw it about durng transport causing seepage of calcium chloride within the apparatus, which fault was very quickly overcome). I can say what a wonderful type of simple robust inflator that was. I think the other bit of advice that might be given is to teach everybody that should they be advancing, they should concentrate very strongly on booty (medical and surgical equipment) as they go forward They never know when they will have to come back again, supply channels will fade out, and I can say very truthfully that a vast number of operations in my small units were undoubtedly carried through successfully by employing booty materials untl lines of supply became established.

Dr. LEECH. The hospital with which I was connected in Sicily had to operate for two months completely on looted equipment. I know what you speak of, Sir.

Here is a series of questions from an American. I am going to take the liberty of stepping outsıde the panel because he asks some direct questions of Dr. Harold 
Griffith in connection with Dr. Gruffith's earlier presentation, and I am going to pass them to Dr. Griffith and let him look them over in the meantime.

Now, Dr. Langton Hewer, here is a question drrected to you, Sir.

\section{QÚestTon 6}

"Dr. Hewer's extremely interestıng paper only touched, as it was intended to, on the physiology etc, of the Trendelenburg position. Would the panel please discuss the necessity for the position beyond say 10 or 15 degrees? With good modern anaesthesia, good relaxation, etc., is it really necessary?"

Dr. Hewer. Well I think myself that it is better not to have Trendelenburg position at all, but if you have to have it, have it as mild as possible and for as short a time as possible. I don't know whether I can add much to that. I thenk-it is perfectly ridiculous with a really good anaesthetic and relaxation. I thunk you might just as well say that to do a gastrectomy you have to hold the patient up by his head I don't see really that there is any necessity to have a pelvis which is completely bare on all sides, it is not necessary at all Careful retraction on a completely relaxed patient will give the surgeon complete access to any part of the pelvis, and, I have never myself seen the necessity for any Trendelenburg position provided, as I say, that the anaesthetic is properly given and the abdommal wall is completely relaxed I don't thunk I should say any more than that, Sir

Dr. LEECH Thank you Is Dr Griffith now leady to answer the questions referred to hm directly?

\section{QUESTION 7}

Dr. Griffith. The questions, Sir, deal mostly with the comparative explosion hazards between Cyclopropane and ether. I don't know that there is much difference in the explosion hazards between Cyclopropane and ether or a mixture of nitrous oxygen, oxygen and ether They are equally dangerous if a source of ignition is in effect set off Some of the Britsh anaesthetssts visitng the United States are extremely apprehensive concerning Cyclopropane explosions, in contrast, and not very apprehensive concerning nitrous oxide, oxygen and ether. [ note that George Thomas's figures bear me out, because there are more explosions with ether than with Cyclopropane, which seem equally dangerous and in the same bracket as we enter into the situation

\section{Question 8}

This next question concerns the so-called Cyclopropane postoperative shock and collapse in the absence of carbon droxide buld-up. Now how do you know there is an absence of $\mathrm{CO}_{2}$ build-up? As Dr, Cullen's paper yesterday or two days ago demonstrated, there is an insidious type of $\mathrm{CO}_{2}$ build-up that we don't know anything about, and in the great preponderance of cases ventilation hasn't been properly done, in many of these cases one does not think there is a $\mathrm{CO}_{2}$ build-up. That, in my opinion, is very often the cause of so-called Cyclopropane 
postoperative shock particularly. There is sometimes an overdosage, not of Cyclopropane, but of other agents we have used at the same time, and that is true perhaps in the postoperative excitement that we sometimes see after Cyclopropane; it may not be the Cyclopropane in itself, it may be the other agents . which were given along with it, for instance in Pentothal induction and preoperative medication with morphine and other drugs.

\section{QUESTION 9}

The next question concerns the capillary ooz.ng in Cyclopropane anaesthesia. Sir Robert Macintosh told a very good story about that the other day. The story was, unless I forget, that a visitng surgeon was in an operating room one day, and the surgeon who was operating was very much opposed to Cyclopropane. He was complaining about the bleeding, and he made the remark, "Oh we always get a lot of bleeding with Cyclopropane." The anaesthetsst said, "What did he cut now?" I do not think that Cyclopiopane is really very much more apt to give oozing under proper operating conditions.

\section{QUESTION 10}

Dr. LEECH. Here is a question-I don't know whether you have to be long or short in replying:

"What place should subarachnord block now be accorded"

Dr. Wyant. I belneve that there is a definite place for subarachnord block. Many indications for this procedure have disappeared. The avallability of the muscle relaxants is one of the arguments of the surgeon, but you cannot get as good muscle relaxation for abdominal operation as you can with subarachnoid spinal anaesthesı. Of course this is true, but there are certain procedures in which it is certainly valuable I personally believe that certain lower abdominal procedures, say Caesarian sections, haemorrhordectomy, and procedures of that sort, are a quite valid indication for subarachnold anaesthesia Of course it depends entirely whom you speak to when you ask for an opinın. Some people will say that there is absolutely no place for this block, and others will almost insist that all operations on the abdomen be done under subarachno1d spinal I beheve that the truth is somewhere in between these two extremes.

Dr. LeECh I should like Professor Macintosh to comment on that question

Professon Macintosh. I should assert, Sir, that the place par excellence for a spinal anaesthetic was with the patient who dislikes to go to sleep. I think if we went around even in this roomful of anaesthetists we should find different religions, different approaches to different subjects, one great difference (surely we have all had it), is between the patient who says "I don't mind what you do with me, as long as you put me to sleep" and the other who says "the only thing I am terrified about is going to sleep." Almost the first thing I say to the patient is "Do you want to remain awake or do you want to go to sleep?" I think it is quite cowardly on our part, if a patient really is trightened of going to sleep, not to give him the spinal if it is indicated. I must encourage, then, a reasonable 
approach to spinal anaesthesia: I should think that we have to differentiate between what the patient needs and what isn't very profitable for our pockets, and the great trouble is, of course, that if you give a spinal and anything goes wrong it's likely to be costly; whereas if you give Pentothali or Cyclopropane (you can't kll them with ether), then of course you can kill them with kindness, and you hear nothing about that.

[Editorial Note. This observation probably reflects the present attitude of British Coroners' Courts.]

Dr. LeEch. Dr. Cope has some views on this subject.

Dr. Cope. I think the question was, Sir, regarding the subarachnoid block. I think that the indications which Professor Macintosh has described are very true indeed. I think there are some strong surgical and medical reasons, such as relief of strangulated hernia in an old man with very severe bronchitis, that type of patient, and Caesarean section too. But is not the necessity for blocking far more safely met perhaps by the extradural approach either through the lumbar region or through the thoracic region? I should have thought that there was now enough evidence that occasionally-and there is no need to say when-one of those dreadful complications occurs with a spinal. I believe I am right in saying that probably can be corrected, but I have recently heard of only one extraordinary case of meningitss following extradural block, and for many years these blocks have been carried out with no evidence at all of any trouble afterwards

\section{QuESTION 1]}

"The Anaesthetic Recovery Room. Where should it take over? Where should it leave off?"

I shall ask Dr. Gain to start this one.

Dr GaIn That was Anaesthetic Recovery Room There is quite a difference between an Anaesthetrc and an Operating Recovery Room. I suppose the Anaesthetic Recovery Room is about the greatest asset we have wangled out of Hospital Administrators in the last twenty years. I thunk it should commence activity the minute the, patient leaves the operating room; the anaesthetist should take the patient to that recovery room and see that all his needs are taken care of. and the patient should remain in that room under trained supervision It is necessary, I think, to have specially trained nurses there, as in any other part of the operating suite, and this room must be next to the operating suite. The patient must remain there, I feel, until he is conscious enough to respond to speech His blood pressure must be stablized, his respiration should be satisfactory, and there should be no signs of recurrent haemorrhage Then, and only then, I think, should the patient be removed. Postoperative recovery rooms as I say are a different problem. The post-anaesthetic recovery room, as I understand it, is, in our experience, an eight-hour shift, so we cannot keep the patient to look after any surgical problems

Dr Sheila Anderson. I think that this is something every hospital should have. I agree with everything that Dr. Gain has said and will not add to it or detract from it. I think the patient should go into the recovery room immediately after 
the operation, be under constant supervision until the anaesthetist is satisfied that there are no complications, and then returned to the ward. This may mean hours or even days.

\section{QuEstion 12}

Dr LEECH Here is another question that was recently handed to me.

"In view of the disease retrolental fibroplasia. what place has oxygen in the treatment and handling of premature babies?"

Dr. Wyant, please.

Dr. Wyant. There is no doubt now, I believe, in most people's minds that retrolental fibroplasia is indeed in part caused by the high oxygen concentrations It is the trend at the present time to try to nurse these babies without the aid of oxygen, and if oxygen is required to control the respiratory distress, we use it intermittently, when needed, and in low concentrations. I had ciccasion to discuss this with our obstetrician, and he feels definitely that any concentration over and above 30 per cent of oxygen in an incubator is harmtul and should not be maintaned for any length of time. 